TP Periodica Polytechnica Mechanical Engineering

\author{
62(2), pp. 101-109, 2018 \\ https://doi.org/10.3311/PPme.10873 \\ Creative Commons Attribution (i)
}

RESEARCH ARTICLE

\section{Thermo-convective Study of a Shell and Tube Thermal Energy Storage Unit}

\author{
Abderrahmane Elmeriah ${ }^{1 *}$, Driss Nehari ${ }^{1}$, Mohamed Aichouni ${ }^{2}$
}

Received 19 April 2017; accepted after revision 03 January 2018

\begin{abstract}
In this paper, we have studied numerically thermo-convective characteristics between a heat transfer fluid (HTF) and phase change material (PCM) in shell and tube thermal energy storage (TES) unit. The paraffin wax is considered as a PCM, filled in a shell which is thermally isolated with the external environment, while the water plays a role of a HTF and flows inside the tube at the moment of charging and discharging cycle. The heat transfer between HTF and PCM is performed by conduction and forced convection, this transfer allows to change the physical state of PCM solid-liquid to obtain a quantity of storable heat in order to create a thermal battery. Enthalpy formulation is used to analyze the heat transfer during melting and solidification process. A good agreement was found between our numerical predictions and the results of the literature. On the other hand, we have investigated the effect of geometrical parameters (tube length and shell diameter) and Reynolds number on the charging and discharging cycles. The obtained results reveal that the tube length and the shell diameter are the most influential parameters on the time of storage system. Similarly, the Reynolds number has much impact on the HTF outlet temperature and the time of solidification and melting process. Furthermore, we have proposed a new thermal storage unit containing the Paraffin wax and RT60 that it gives us a good rate and time of storage compared to the first unit that has only the paraffin wax.
\end{abstract}

\section{Keywords}

heat transfer fluid, phase change material, latent heat storage, shell and tube

\footnotetext{
${ }^{1}$ Smart Structure Laboratory, University Center of Ain-Temouchent, 46000 Ain-Temouchent, Algeria

${ }^{2}$ The Engineering College, University of Hail, P.O. Box 2440, Hail, Saudi Arabia

*Corresponding author, e-mail: elmeriahabderrahmane@gmail.com
}

\section{Introduction}

The problems of energies consumption have aggravated due to the increase of industrial, commercial and residential activities; parallelly, the current technological development suffers from the depletion of fossil energy. In such case, there is a huge need to use renewable energy sources because they represent a good solution to such problems, and among the known renewable energies, the thermal solar remains the most exploited type. As it is unstable along the time (day and night) and due to its periodic nature, we must use a thermal energy storage device in order to ensure the continuity of this energy during the time. Amongst the types of thermal storage systems, there is the thermal latent heat storage based on the use of phase change materials (PCMs) which have advantages such as high storage density. Many numerical and experimental studies were performed on the latent thermal energy storage systems.

From the previous studies of Yang et al. [1] and Trp et al. [2], the thermal storage depends mainly on the HTF inlet velocity (or mass flow rate), HTF inlet temperature, and geometric parameters. Therefore, the choice of the operating conditions and geometric parameters depends on the required heat transfer rate and the time storage in which the energy will be stored or delivered according to Trp et al. [2]. In order to explore the effect of the adequate choice of the PCM, El Qarnia [3] has studied numerically the thermal performance of a solar latent heat storage unit (LHSU) during charging and discharging cycle by using three kinds of PCMs (n-octadecane, Paraffin wax and Stearic acid) as storage mediums. The results showed that a water production at high temperature depends on the careful selection of PCMs. Recently, Tao and Carey [4] have investigated experimentally the effect of PCM thermo-physical characteristics on the performance of shell and tube LHSU in order to improve its performance. The results have showed that the PCM thermo-physical characteristics are the responsible parameters to improve the time and heat transfer of the system. A phase change process dominated by heat conduction in a shell and tube TES unit has been studied experimentally and numerically by solving a developed analytical model by Kibria et al. [5] for a medium temperature of melting. In order to evaluate the time 
of solidification and melting process in terms of HTF outlet temperature, various physical and geometric parameters have been conducted. The results revealed that the inlet temperature of HTF and inner diameter of tube have a strong effect on the heat exchange rate during phase change process compared to the impact of HTF mass flow rate and tube thickness.

A numerical and experimental investigation has been carried out by Hosseini et al [6] using the commercial paraffin RT50 (Rubitherm $\mathrm{GmbH}$ ) as PCM. Their results revealed that a rising of $\mathrm{HTF}$ inlet temperature from $70^{\circ} \mathrm{C}$ to 75 and $80^{\circ} \mathrm{C}$ at a constant flow rate of $1 \mathrm{~L} / \mathrm{min}$ allows to increase the theoretical efficiency in charging and discharging process from $81.1 \%$ to $88.4 \%$ and $79.7 \%$ to $81.4 \%$ respectively. Recently, an experimental study on the vertical shell and tube latent heat thermal storage (LHTS) unit has been conducted by Wang et al. [7], the erythritol was considered as PCM and the air has been chosen as HTF, which flows downward during charging and discharging cycle. Their results clarify that the increase of the HTF mass flow rate and inlet temperature reduces the charging process time, while the air inlet pressure has a small effect on the heat transfer inside a PCM.

Concerning the geometry of the shell, a comparative study for two-dimensional solidification process was done numerically by Mosaffa et al. [8] between cylindrical shell and rectangular storages LHSU having the same volume and heat transfer area where the air was considered as HTF. On the one hand, it has found that the solidification rate of PCM in cylindrical shell is much better and rapidly compared to the rectangular shape. On the other hand, the low thermal conductivity of PCM limits the heat transfer rate during both charging and discharging processes. In order to enhance the heat transfer exchange during such processes, extended surface (fins) are used. In this sense, Zhang and Faghri [9] investigated numerically the effect of internal longitudinal fins. The authors have demonstrated the effectiveness of the fins to improve the heat transfer, while the melting volume fraction (MVF) can be significantly increased by increasing the thickness, height and number of fins.

On the other hand, Al-Abidi et al. [10] have investigated numerically using the commercial code Fluent 6.3.26 the triplex tube heat exchanger (TTHX). A different effect of geometric parameters were considered, such as the internal and external fins, the fin length, number of fins, and fin thickness, in order to accelerate the melting rate of RT82 as a PCM. The results have shown that these parameters have a significant influence on the thermal behavior of melting process, whereas the effect of fin thickness is small compared to the fin length and number of fins, which have a strong effect on the melting rate time. A numerical study was carried out by Tao et al. [11] for phase change thermal energy storage (PCTES) unit used in a dish solar thermal system for high temperature storage.

The effect of the enhanced tubes has been studied on the behavior of PCM melting by adopting three enhanced tubes, namely dimpled tube, cone-finned tube and helically-finned tube. The results show that compared with the smooth tube, all of the three enhanced tubes could improve the PCM melting rate. Among the previous works, the TES unit of Kibria et al. [5] could be useful to be investigated using numerical modeling, in order to improve it by proposing several configurations. In this sense, a two-dimensional and axisymmetric physical model was used to investigate the effect of the physical and geometric parameters not considered by the last authors such as the tube length, shell inner diameter and Reynolds number variation; parameters that were not considered earlier by Kibria et al. [5] would contribute to improve the thermal performance of the energy storage unit. Moreover, an improved thermal storage unit is proposed which contains two phase change materials (PCMs), separated longitudinally inward the shell space and have a close melting point and different thermal characteristics.

\section{Mathematical model}

The PCTES unit under investigation is shown in Fig. 1. Two different configurations of this unit were studied: (I) shell-andtube system with paraffin wax; and (II) shell-and-tube system with paraffin wax and RT60. The first configuration consists of a shell-and-tube configuration (see Fig. 1.a) that has been used previously by Kibria et al. [5]. The inner tube is made of copper. Distilled water flows through the inner tube as HTF. The phase change material (paraffin wax) fills the annular space. The outer surface of the storage unit is well insulated. The second system shown in Fig. 1(c) is similar to the first configuration concerning the inner tube, HTF used and the outer surface of the storage, but two different phase change materials namely the paraffin wax and RT60 separated by a second tube of copper are used. As the problem under examination is axisymmetric, a schematic 2-D computational domain for all investigated cases is presented for both configuration in the plots Fig. 1(b) and Fig. 1(d). Since the same geometry of Kibria et al. [5] was considered here, the same hypothesis, boundary and initial conditions are adopted in the present study:

(i) The thickness of the inner tube wall is considered;

(ii) The thermo-physical properties of HTF and PCM are constant with respect to the temperature;

(iii) The initial temperature of the latent thermal storage unit is uniform;

(iv) HTF flow is laminar;

(v) Natural convection inside the Paraffin wax was not considered, as the considered shell and tube thermal energy storage unit used is horizontal.

During the charging cycle, the HTF flows inside the tube by inlet temperature of $88^{\circ} \mathrm{C}$ and a mass flow rate of $0.072 \mathrm{~kg} / \mathrm{min}$. On the other hand, during the discharging after storage, we took the heat stored using cold HTF passage by a temperature 
(a) Configuration I

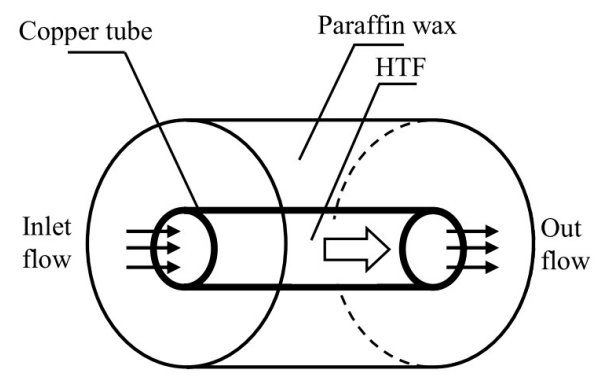

(c) Configuration II

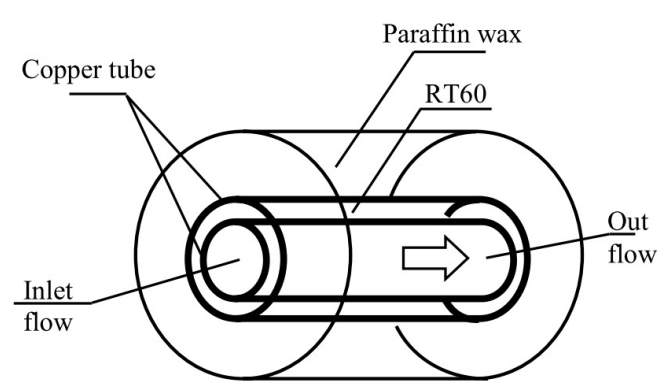

(b) 2D representation of Configuration I

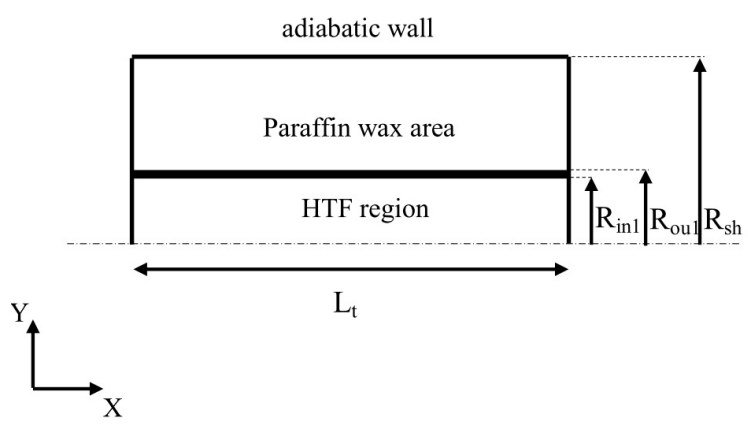

(d) $2 \mathrm{D}$ representation of Configuration II

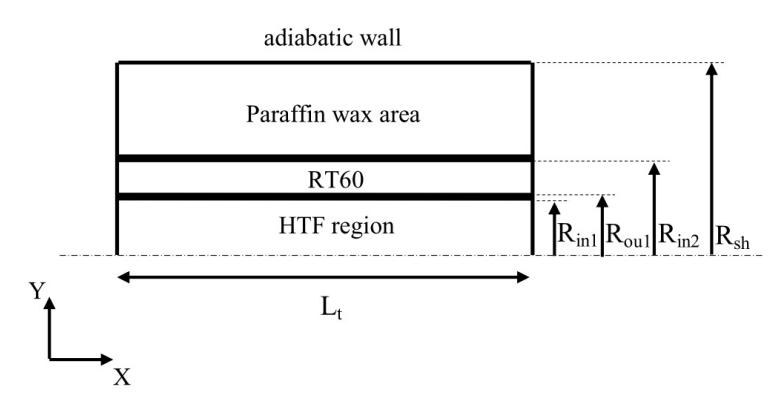

Fig. 1 Latent heat storage unit

of $25^{\circ} \mathrm{C}$ and a mass flow rate of $0.07 \mathrm{~kg} / \mathrm{min}$ as used in the experimental work of Kibria et al. [5]. The thermo-physical properties of phase change materials with water as HTF which are used in the present investigation are shown in Table 1. This two-dimensional problem is governed by unsteady energy and Navier-stokes equations:

The continuity:

$$
\frac{\partial}{\partial x_{i}}\left(\rho u_{i}\right)=0
$$

The momentum:

$$
\frac{\partial}{\partial t}\left(\rho u_{i}\right)+\frac{\partial}{\partial x_{i}}\left(\rho u_{j} u_{i}\right)=\mu \frac{\partial^{2} u_{i}}{\partial x_{i} \partial x_{j}}-\frac{\partial p}{\partial x_{i}}+S_{i}
$$

The energy:

$$
\frac{\partial}{\partial t}(\rho h)+\frac{\partial}{\partial x_{i}}\left(\rho u_{i} h\right)=\frac{\partial}{\partial x_{i}}\left(k \frac{\partial T}{\partial x_{i}}\right)+S_{h}
$$

Where $\rho$ is the density, $k$ denotes the thermal conductivity, $\mu$ is the dynamic viscosity, $S_{i}$ and $S_{h}$ are the source terms, $u_{i}$ is the velocity component in the i-direction, $x_{i}$ is a cartesian coordinate and $h$ is the specific enthalpy.

The sensible enthalpy $h_{S}$ is given by:

$$
h_{s}=h_{r e f}+\int_{T_{r e f}}^{T} C_{p} d T
$$

And the total enthalpy, $H$ is defined as

$$
H=h_{s}+\Delta H
$$

Where $\Delta H=\gamma L$ is the enthalpy change due to phase change, $h_{r e f}$ is the reference enthalpy at the reference temperature $T_{r e f}, C_{p}$ is the specific heat, $L$ is the specific enthalpy of melting (liquid

\begin{tabular}{|c|c|c|c|c|c|c|c|c|c|c|}
\hline \multirow[t]{2}{*}{ PCM } & \multicolumn{2}{|c|}{$\begin{array}{l}\text { Density } \\
{\left[\mathrm{kg} / \mathrm{m}^{3}\right]}\end{array}$} & \multicolumn{2}{|c|}{$\begin{array}{c}\text { Specific heat } \\
{[\mathrm{J} / \mathrm{kg} \mathrm{K}]}\end{array}$} & \multirow[t]{2}{*}{$\begin{array}{l}\text { Latent heat } \\
{[\mathrm{J} / \mathrm{kg}]}\end{array}$} & \multicolumn{2}{|c|}{$\begin{array}{l}\text { Thermal conductivity } \\
\qquad[\mathrm{W} / \mathrm{m} \cdot \mathrm{K}]\end{array}$} & \multicolumn{2}{|c|}{$\begin{array}{l}\text { Dynamic viscosity } \\
{\left[\mathrm{N} \mathrm{s} / \mathrm{m}^{2}\right] \text { or }[\mathrm{kg} / \mathrm{m} \mathrm{s}]}\end{array}$} & \multirow[t]{2}{*}{$\begin{array}{c}\text { Melting Temperature } \\
{\left[{ }^{\circ} \mathrm{C}\right]}\end{array}$} \\
\hline & Solid & Liquid & Solid & Liquid & & Solid & Liquid & Solid & Liquid & \\
\hline Paraffin wax & 910 & 790 & 2000 & 2150 & 190000 & 0.24 & 0.22 & - & 0.004108 & 61 \\
\hline RT60 & 880 & 770 & 2660 & 2340 & 123506 & 0.2 & 0.2 & - & 0.00003705 & $53 \sim 61$ \\
\hline \multicolumn{11}{|c|}{ Heat transfer fluid (HTF) } \\
\hline Water at $25^{\circ} \mathrm{C}$ & \multicolumn{2}{|c|}{997} & \multicolumn{2}{|c|}{4179} & & \multicolumn{2}{|c|}{0.613} & \multicolumn{2}{|c|}{0.000855} & \\
\hline Water at $88^{\circ} \mathrm{C}$ & \multicolumn{2}{|c|}{967.1} & \multicolumn{2}{|c|}{4203} & & \multicolumn{2}{|c|}{0.674} & \multicolumn{2}{|c|}{0.000324} & 0 \\
\hline
\end{tabular}
state) and $\gamma$ is the liquid fraction during the phase change which occur over a range of temperatures $T_{\text {solidus }}<T<T_{\text {Liquidus }}$ defined by the following relation $6 .(a, b, c)$ :

Table 1 Thermo-physical properties of PCMs and HTF [12-14] 
If:

$$
\left\{\begin{array}{l}
T<T_{\text {solidus }}(\text { solid state }): \gamma=\frac{\Delta H}{L}=0(a) \\
T_{\text {solidus }}<T<T_{\text {liquidus }}(\text { Mushy state }): 0<\gamma=\frac{\Delta H}{L}<1(b) \\
T>T_{\text {liquidus }}(\text { liquid state }): \gamma=\frac{\Delta H}{L}=1(c)
\end{array}\right.
$$

\section{The Numerical method and the grid used}

The governing equations are solved by using the commercial code FLUENT 17 with the first order implicit scheme for the time and the second order upwind scheme for the space. Moreover, the SIMPLE algorithm is used.

The local criterion for numerical convergence, i.e. the maximum relative difference between two consecutive iterations is imposed less than $10^{-6}$. The computational grids in the (xy) plane have been obtained using the non-uniform Quadratic elements type of mesh to simulate the axisymmetric geometry. These structured quadratic cells are created with fine mesh near the walls using mesh generation software ANSYS GAMBIT 2.4.6.

A dense grid distribution is employed near the wall while a uniform grid distribution is used in the streamwise direction. The plots of Fig. 2.a and Fig. 2.b show the typical grid distribution over the computational domain of the configurations I and II. The accuracy of the solution depends on the number and the size of the cells. The grid size used in the computations is chosen by performing a grid independence study (see Fig. 3).

(a) A part of the grid for conf I

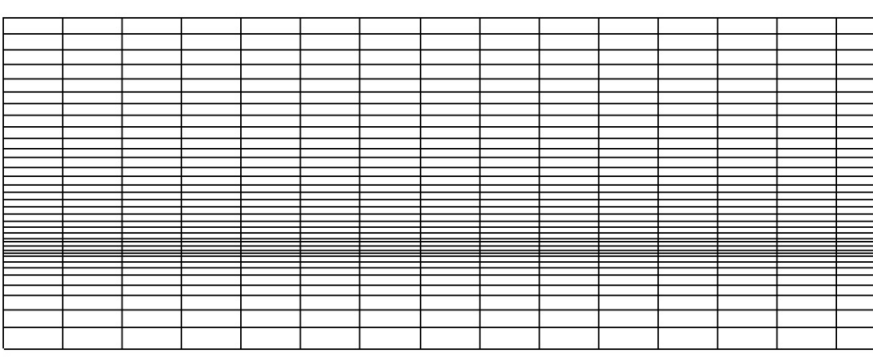

(b) A part of the grid for conf II

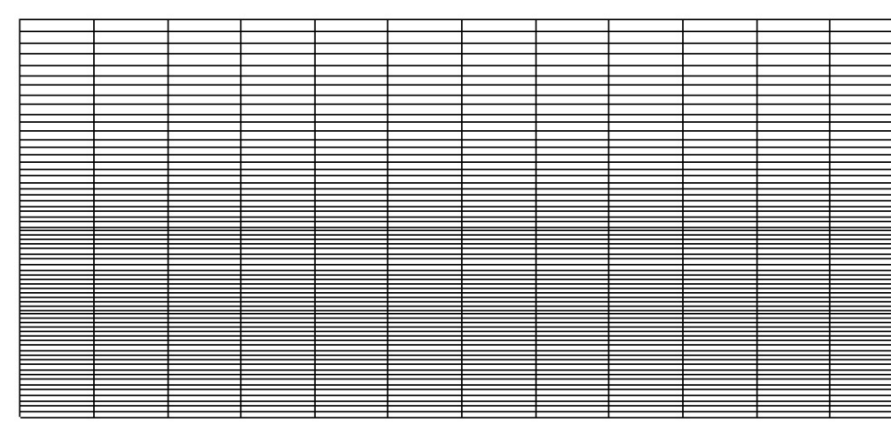

Fig. 2 The grid used in first (I) and second (II) configuration

For the first configuration, several meshes were tested to ensure that the solution was independent of the mesh $(35 \times 300$; $50 \times 300 ; 65 \times 300)$. This test indicated that $35 \times 300$ cells are adequate. On the other hand, concerning the second configuration (Case A and B) the analysis of the grid independency made for the grid tests $(50 \times 300 ; 65 \times 300 ; 85 \times 300)$ indicate (not shown here) that $65 \times 300$ cells are adequate. From above we can say that the grid $(35 \times 300)$ is suitable for the first configuration and the grid $(65 \times 300)$ is convenient for the second configuration.

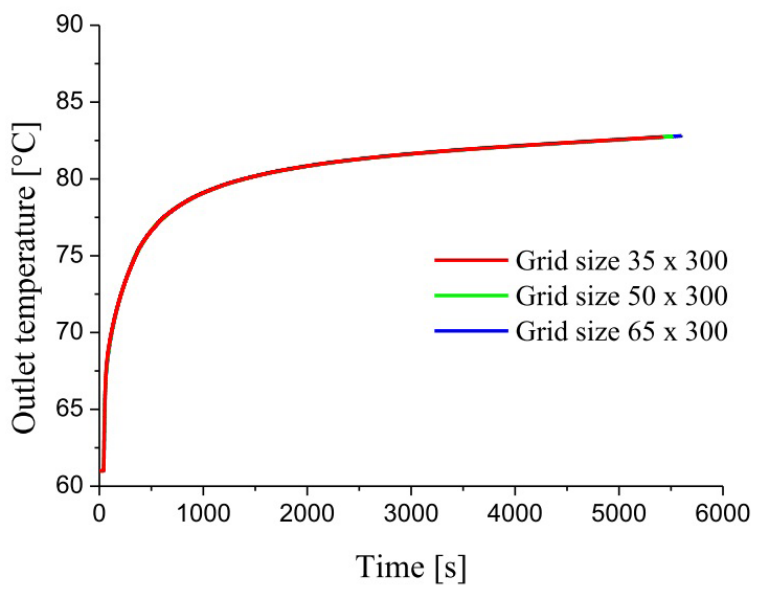

Fig. 3 Outlet temperature in charging cycle in different grid size of configuration I

\section{Results and discussion}

Before performing the study of parameters effect on the thermal storage, the validation of the numerical results was performed in charging and discharging cycle through a comparison with the experimental and numerical results of Kibria et al. [5] for the parameters presented in Table 2.

Table 2 Geometric parameters of the configuration I (configuration of Kibria et al. [5])

\begin{tabular}{lllc}
\hline The inner radius of tube 1 & $\left(\mathrm{R}_{\text {in1 }}\right)$ & {$[\mathrm{m}]$} & 0.0054 \\
\hline The outer radius of tube 1 & $\left(\mathrm{R}_{\text {ou1 }}\right)$ & {$[\mathrm{m}]$} & 0.006 \\
The radius of the shell & $\left(\mathrm{R}_{\text {sh }}\right)$ & {$[\mathrm{m}]$} & 0.018 \\
The length of tube & $\left(\mathrm{L}_{\mathrm{t}}\right)$ & {$[\mathrm{m}]$} & 1 \\
Thickness of tube 1 & & {$[\mathrm{m}]$} & 0.0006 \\
\hline
\end{tabular}

\subsection{Validation}

The validation was performed on the evolution of HTF outlet temperature at the charging and discharging cycle. The comparison between our numerical results in relation to the analytical and experimental results of Kibria et al. [5] showed a good agreement in Fig. 4.

At the charging cycle, the PCM is initially at solid state (at the temperature $61^{\circ} \mathrm{C}$ ) and the HTF circulates with inlet temperature equal to $88^{\circ} \mathrm{C}$, following the boundary and initial conditions of Kibria et al. [5]. The HTF outlet temperature increases over time until asymptotic value of $83^{\circ} \mathrm{C}$ which is lower than the inlet temperature $\left(88^{\circ} \mathrm{C}\right)$. This difference is due to the heat absorption by melting Paraffin wax. The results show 

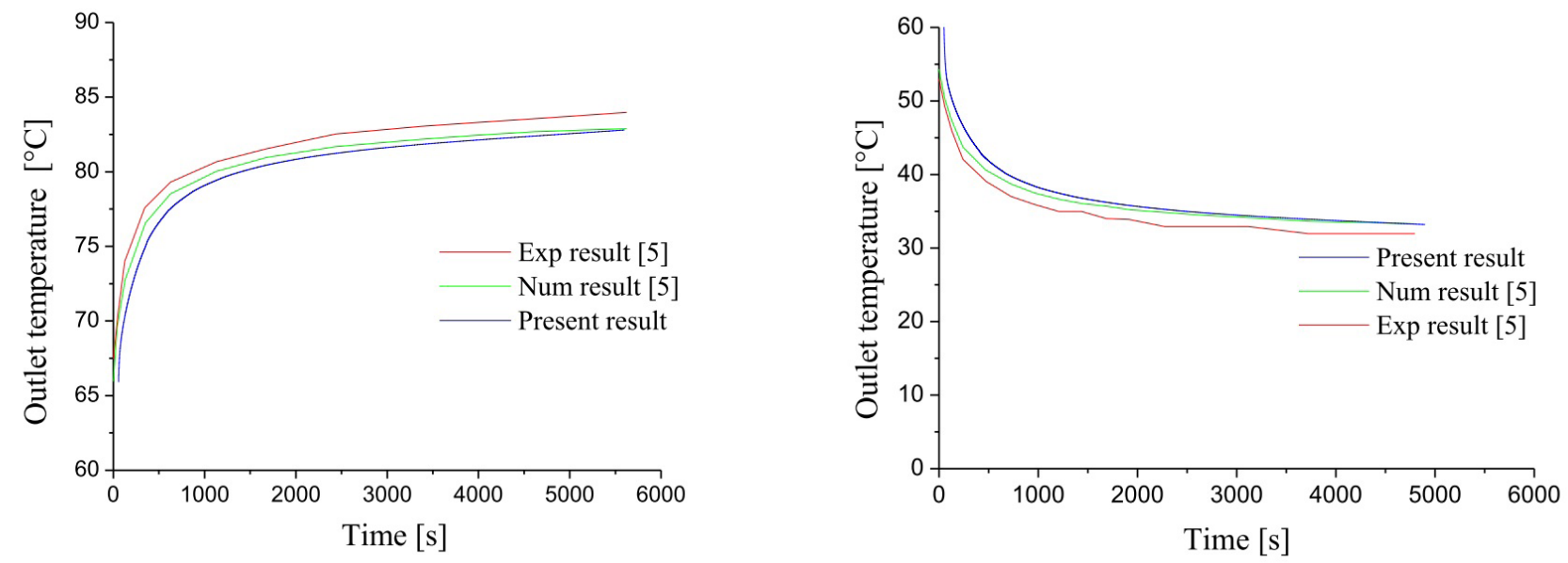

Fig. 4 Validation of HTF outlet temperatures in charging and discharging cycle

that the outlet temperature of system is close to those obtained analytically and experimentally by Kibria et al. [5], where this process took about 6500 s to complete the charging cycle. In discharging process, the HTF absorbs the heat stored in the Paraffin wax whereas the HTF outlet temperature decreases over time until asymptotic value $33^{\circ} \mathrm{C}$ and the paraffin wax becomes in the solid state. The small discrepancy between the numerical results and those obtained experimentally is due to the simplifications considered in the numerical model. Further validations (not shown here) done for several parameters give a good agreement with the numerical and experimental data of the literature [5].

\subsection{Parametric study}

In this investigation, we have made a parametric study following the measures of the first configuration (Table 2) based to examine the effect of: (i) length of tube; (ii) shell diameter; and (iii) Reynolds number on the time and rate of charging and discharging process. Furthermore, we have tried

(a) Charging

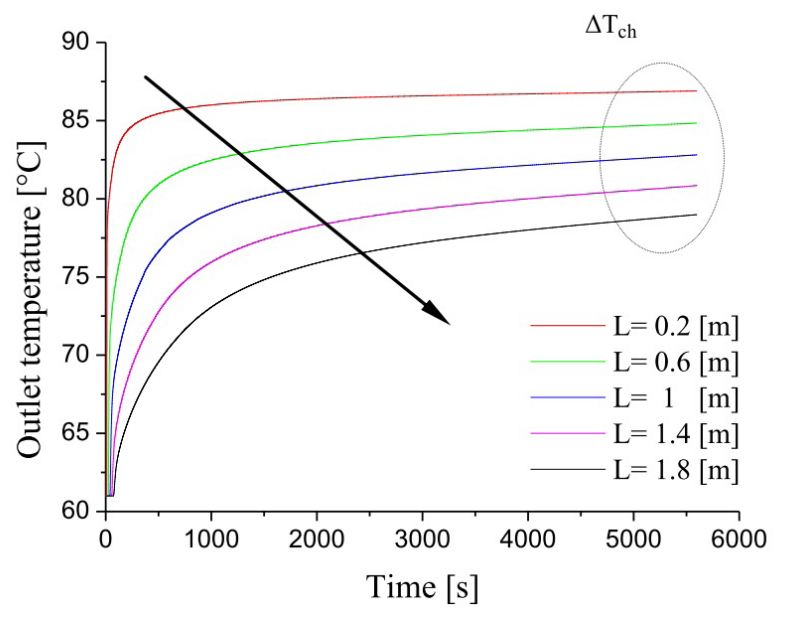

to propose a new thermal unit composed of a Paraffin wax and RT60. The performances of this new configuration will be compared to the first one.

\subsubsection{Influence of tube length}

Fig. 5 shows the effect of different tube length $L_{t}$ on the thermal performance during the charging and the discharging cycles. Considering the first configuration, we have changed the tube length in the range $0.2-1.8 \mathrm{~m}$ in the scope to quantify this effect for the charging and discharging cycles. From this figure which depicts outlet temperature of HTF versus the tube length variation in the range $0.2-1.8 \mathrm{~m}$. We can see that the time of charging and discharging cycles is proportional to the tube length. An increase of the length leads to an increase of the melting and solidification time. Moreover, the increase of tube length decreases the asymptotic value of the HTF outlet temperature from $87^{\circ} \mathrm{C}$ in the case $L_{t}=0.2 \mathrm{~m}$ to $79^{\circ} \mathrm{C}$ in the case $L_{t}=1.8 \mathrm{~m}$ during $5600 \mathrm{~s}$. This leads to a gradient of temperature $\Delta T_{c h}$ equal to $8^{\circ} \mathrm{C}$ between HTF outlet temperatures of tube

(b) Discharging

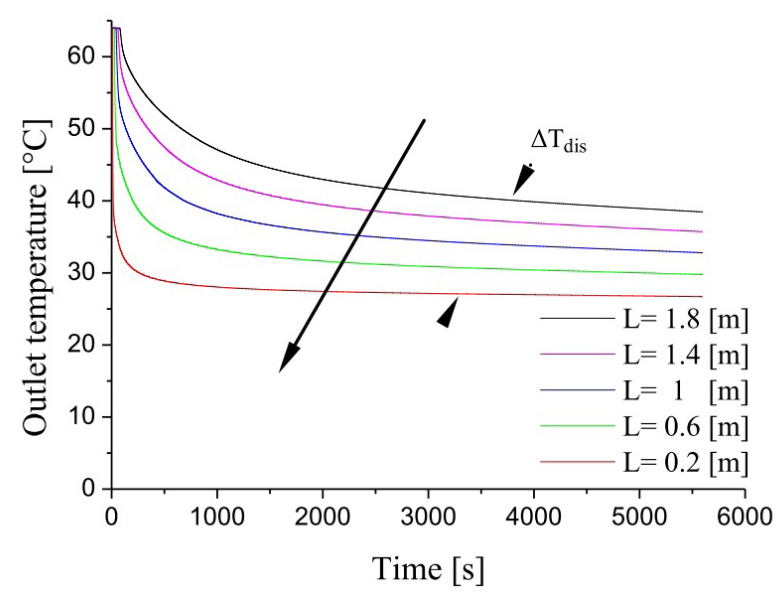

Fig. 5 Effect of tube length in charging and discharging cycle 
length from $0.2 \mathrm{~m}$ to $1.8 \mathrm{~m}$ at charging time. With regard to the discharging process and the effect of increasing the tube length, the asymptotic value of the HTF outlet temperature increases from $25^{\circ} \mathrm{C}$ to $38.5^{\circ} \mathrm{C}$ along the $5600 \mathrm{~s}$, thus leading to a gradient of temperature $\Delta T_{d i s}$ equal to $13.5^{\circ} \mathrm{C}$. From this figure, it can be seen that the tube length is an important parameter to optimize the melting and solidification time.

\subsubsection{Effect of shell diameter}

The shell diameter is among the important parameters that have a relation with the progress of solidification and melting. In this case we have changed the shell diameter in the range 24-44 mm. Fig. 6 shows that the shell diameter reduction allows to complete the discharging and charging rate in a short time. The reduction of shell diameter causes the minimizing of the PCM mass volume. This allows accelerating the heat charging or discharging of the mass through heat transfer process. This contributes to speed up the melting fraction rate of the Paraffin wax during charging process.

It can be seen from the figure, that the shell diameter of 24 mm needs just 3300s to complete almost the charging or the discharging processes, whereas the other cases needed more than 5000s to complete the fully charging or discharging processes. As a result, the gradient in HTF outlet temperature between the shells of minimum and maximum diameter used $\Delta T_{c h}$ is equal to $5^{\circ} \mathrm{C}$ for charging process and $\Delta T_{d i s}$ is about $8^{\circ} \mathrm{C}$ for discharging process. Therefore, the quantity of Paraffin wax must be appropriate with the work conditions, in order to optimize the time of storage system.

\subsubsection{Effect of Reynolds number}

As we know, the Reynolds number depends on the HTF properties as the viscosity, velocity, and the size of the tube. In the present investigation, only the laminar regime is considered for the flow of HTF. In this contribution, the effect of Reynolds number is investigated in the range $\mathrm{Re}=100-1500$. The increase of Reynolds number allows to decrease the solidification and melting time as shown in the Fig. 7. It is clear from this figure, that for the charging cycle and for the high value of Reynolds number $(\mathrm{Re}=1500)$ the HTF outlet temperature tends to reach the asymptotic value of $86.5^{\circ} \mathrm{C}$, while for the lower value of Reynolds number (100), the HTF outlet temperature tends to reach the asymptotic value of $69.5^{\circ} \mathrm{C}$. Therefore, the temperature gradient $\Delta T_{\text {dis }}$ of HTF outlet temperature in discharging cycle is about $9.6^{\circ} \mathrm{C}$ and in the charging case $\Delta T_{c h}$ is $17^{\circ} \mathrm{C}$.

\subsubsection{Improvement of TES unit}

According to the above results, it could be very useful to find an effective way that allows the PCM to absorb the maximum heat provided by the HTF. As a result, we have tried to propose a new configuration (Fig. 1(d)), where we inserted a layer of another phase change material namely the RT60, that its melting temperature is equal to $57^{\circ} \mathrm{C}$, which is very close to melting temperature of the paraffin wax (equal to $61^{\circ} \mathrm{C}$ ). This layer of RT60 makes it possible to distribute the thermal load on the paraffin wax along the axial direction and to ensure it the thermal inertia. In this TES unit, the two PCMs are superposed between the copper tubes. Therefore, the heat exchange in this unit is done by conduction in two steps; (i) heat interchange between HTF and RT60 through the first copper tube, (ii) heat transfer from the RT60 into the paraffin wax through the second copper tube. The same boundary and initial conditions adopted in the first configuration are used here. Different cases according to Table 3 and Table 4 are numerically predicted. The melting temperature of RT60 is lower than the paraffin wax $\left(61^{\circ} \mathrm{C}\right)$, which allows the RT60 to melt before the paraffin wax, which leads to accelerate the melting process of RT60 and its solidification process due to its rapid heat absorption from the HTF.

In this configuration we proposed two cases A and B. The case A (see Table 3 ) has a constant radius of the shell $R_{s h}$ and a variable inner radius of the second tube $R_{\text {in } 2}$ that consequently reduces the volume of Paraffin wax. This radius is varied in the (a) Charging

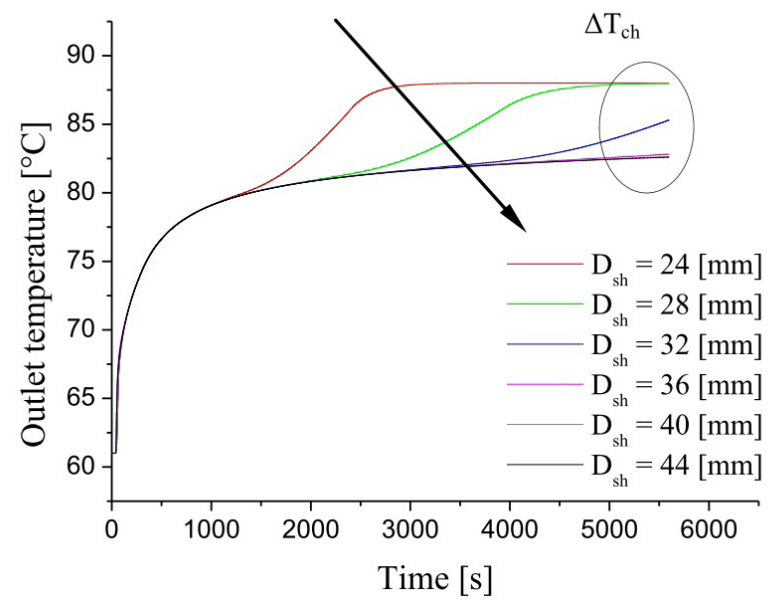

(b) Discharging

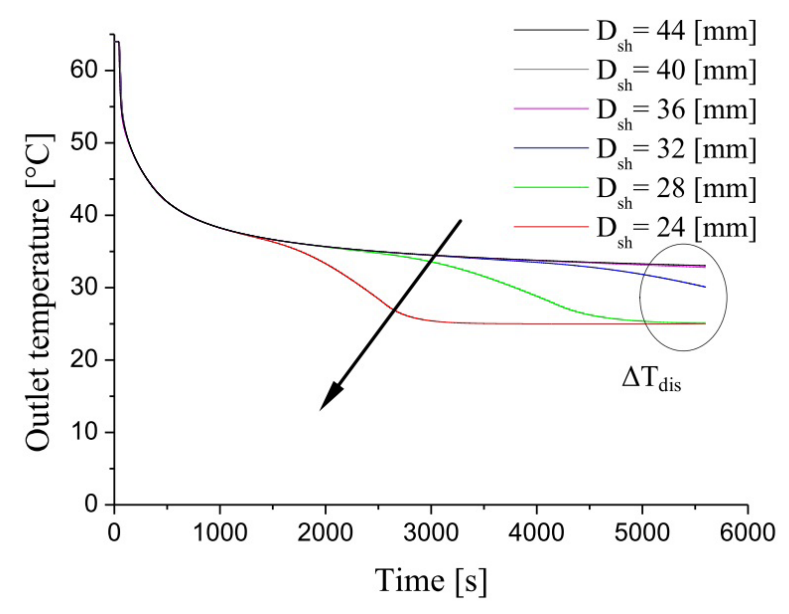

Fig. 6 Effect of shell diameter in charging and discharging cycle 
(a) Charging

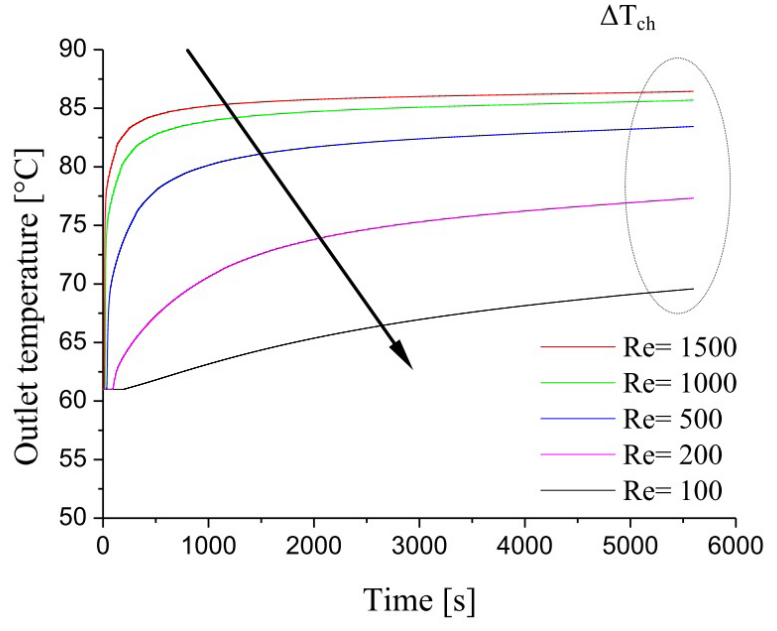

(b) Discharging

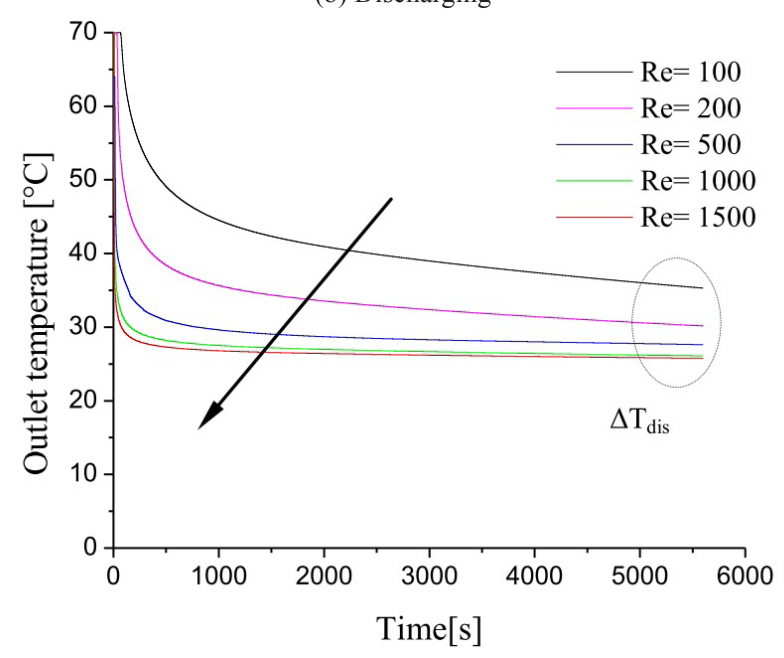

Fig. 7 Effect of Reynolds number in charging and discharging cycle

Table 3 Geometric parameters of the second configuration II.A

\begin{tabular}{|c|c|c|c|c|c|c|}
\hline The inner radius of tube 1 & $\left(\mathrm{R}_{\mathrm{in} 1}\right)$ & {$[\mathrm{m}]$} & 0.0054 & & & \\
\hline The outer radius of tube 1 & $\left(\mathrm{R}_{\text {oul }}\right)$ & {$[\mathrm{m}]$} & 0.006 & & & \\
\hline The inner radius of tube 2 & $\left(\mathrm{R}_{\mathrm{in} 2}\right)$ & {$[\mathrm{m}]$} & 0.008 & 0.01 & 0.012 & 0.014 \\
\hline The radius of the shell & $\left(\mathrm{R}_{\mathrm{sh}}\right)$ & {$[\mathrm{m}]$} & 0.018 & & & \\
\hline The length of tube & $\left(\mathrm{L}_{\mathrm{t}}\right)$ & {$[\mathrm{m}]$} & 1 & & & \\
\hline The thickness of copper tube 1 and 2 & & {$[\mathrm{~m}]$} & 0.0006 & & & \\
\hline
\end{tabular}

Table 4 Geometric parameters of the second configuration II.B

\begin{tabular}{lllllll}
\hline The inner radius of tube 1 & $\left(\mathrm{R}_{\text {in } 1}\right)$ & {$[\mathrm{m}]$} & 0.0054 & & & \\
\hline The outer radius of tube 1 & $\left(\mathrm{R}_{\mathrm{ou1}}\right)$ & {$[\mathrm{m}]$} & 0.006 & & & \\
The inner radius of tube 2 & $\left(\mathrm{R}_{\mathrm{in} 2}\right)$ & {$[\mathrm{m}]$} & 0.008 & 0.01 & 0.012 & 0.014 \\
The radius of the shell & $\left(\mathrm{R}_{\mathrm{sh}}\right)$ & {$[\mathrm{m}]$} & 0.01902 & 0.02001 & 0.02114 & 0.02239 \\
The length of tube & $\left(\mathrm{L}_{\mathrm{t}}\right)$ & {$[\mathrm{m}]$} & 1 & & & \\
\hline
\end{tabular}

range $0.008-0.014 \mathrm{~m}$. The variation of the inner radius allows us to obtain several proportions in the volume of the two PCMs, from the case the existence of only the Paraffin wax to the case we obtain the Paraffin wax with RT60 $\left(R_{i n 2}=0.014 \mathrm{~m}\right)$. The results shown in Fig. 8 indicate a decrease in the time of charging and discharging cycles compared to case of the first thermal storage unit (containing only Paraffin wax), whereas the temperature gradient $\Delta T_{c h}$ of the HTF outlet temperature in charging cycle increases in the first time period [0-1500s], then starts to decline. Near the time 4000s, we remark an increase of the outlet temperature and $\Delta T_{c h}$. This is due to the PCMs which have achieved the total phase change from the solid to liquid and we are in sensible phase of heat transfer. In case B (Table 4), we have fixed the volume of Paraffin wax (same volume of the first configuration) and we have varied the inner radius of the second tube $R_{i n 2}$ from 0.008 to $0.014 \mathrm{~m}$, which means the shell radius will vary. In this case the time of charging and discharging cycle also decreases compared to the use of a Paraffin wax alone as presented in Fig. 9. This case is more stable in charging and discharging cycles than case A, as the mass volume of the PCMs of the case B is increased compared to the first case A. However, both cases have a better evolution of the HTF temperature than the paraffin wax alone as shown in Fig. 8 and Fig. 9.

\section{Conclusion}

As the appropriate choice of the physical and geometric parameters allows to optimize the thermal storage unit, the present study was devoted to examine the effect of these parameters on the shell and tube thermal energy storage unit that investigated previously by Kibria et al. [5]. Moreover, improvements of this storage unit were investigated through new configurations. A twodimensional numerical method based on the Enthalpy formulation has been used to predict the heat transfer between HTF and PCM. The laminar forced convection inside the tube during charging and discharging process was considered, whereas the natural convection has been ignored inside the PCM enclosure. 
(a) Charging case

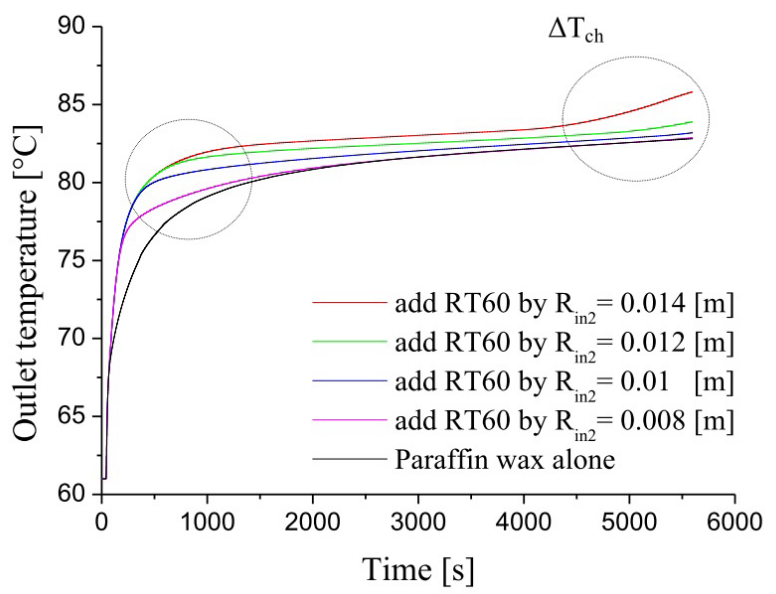

(b) Discharging case

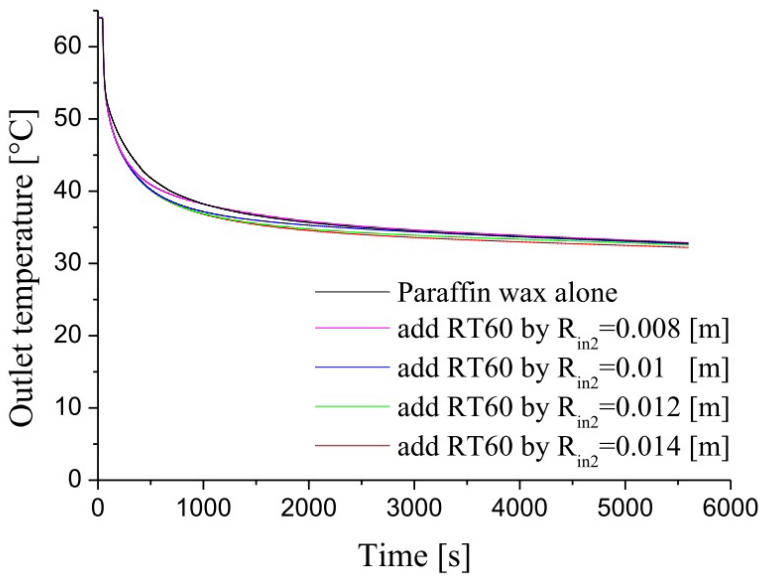

Fig. 8 Charging and discharging cycle of the second configuration II.A

(a) Charging case

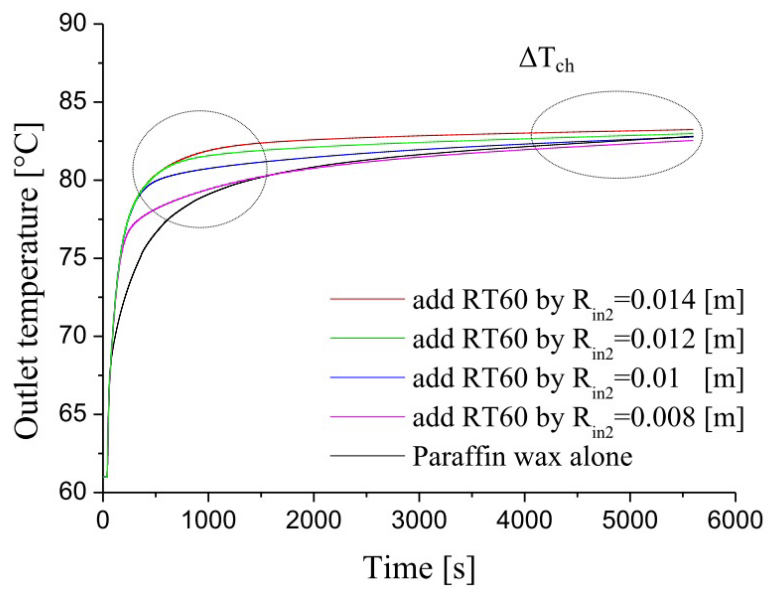

(b) Discharging

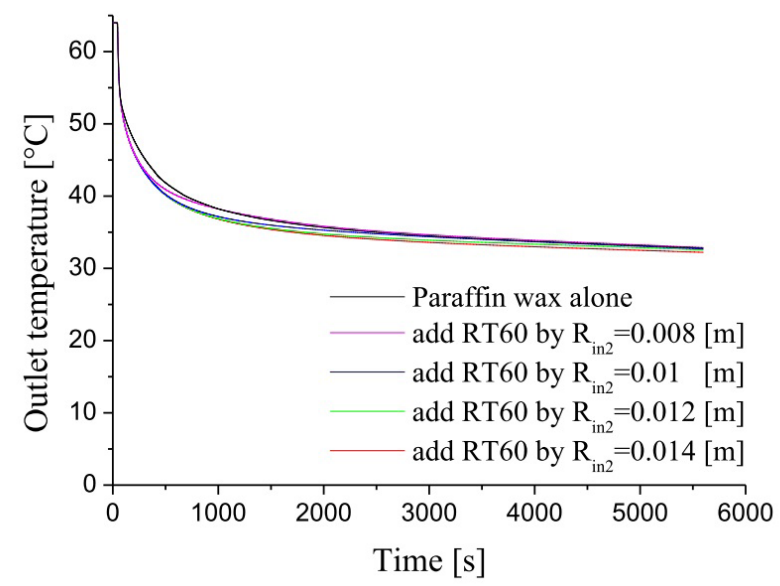

Fig. 9 Charging and discharging cycle of the second configuration II.B

A parametric study has been conducted in order to study the effect of the tube length, shell diameter and Reynolds number. Improvement of the thermal performances of this unit was proposed and investigated.

The results of the parametric study have shown that the tube length and shell diameter have a great effect on the HTF outlet temperature, moreover the Reynolds number is the most influential parameter which has an impact on the time and rate of solidification and melting process.

From the present results, the design parameters should be selected carefully in order to optimize the performance of the storage unit. In addition to that, the new thermal energy storage unit filled by RT60 and Paraffin wax allowed for better efficiency of the rate storage and HTF outlet temperature compared to the unit containing only the Paraffin wax.

\section{Acknowledgments}

This work was carried out in the Laboratory of Smart Structure; the authors would like to acknowledge the support of the university center of Ain-Temouchent.

\section{References}

[1] Yang, X., Li, Y., Lu, Z., Zhang, L., Zhang, Q., Jin, L. "Thermal and Fluid Characteristics of a Latent Heat Thermal Energy Storage Unit." Energy Procedia. 104, pp. 425-430. 2016.

https://doi.org/10.1016/j.egypro.2016.12.072

[2] Trp, A., Lenic, K., Frankovic, B. "Analysis of the influence of operating conditions and geometric parameters on heat transfer in water-paraffin shell-and-tube latent thermal energy storage unit." Applied Thermal Engineering. 26(16), pp. 1830-1839. 2006.

https://doi.org/10.1016/j.applthermaleng.2006.02.004

[3] El Qarnia, H. "Numerical analysis of a coupled solar collector latent heat storage unit using various phase change materials for heating the water." Energy Conversion and Management. 50 (2), pp. 247-254. 2009. https://doi.org/10.1016/j.enconman.2008.09.038

[4] Tao, Y. B., Carey, V. P. "Effects of PCM thermophysical properties on thermal storage performance of a shell-and-tube latent heat storage unit." Applied Energy. 179, pp. 203-210. 2016.

https://doi.org/10.1016/j.apenergy.2016.06.140

[5] Kibria, M. A., Anisur, M. R., Mahfuz, M. H., Saidur, R., Metselaar, I. H. S. C. "Numerical and experimental investigation of heat transfer in a shell and tube thermal energy storage system." International Communications in Heat and Mass Transfer. 53, pp. 71-78. 2014. https://doi.org/10.1016/j.icheatmasstransfer.2014.02.023 
[6] Hosseini, M. J., Rahimi, M., Bahrampoury, R. "Experimental and computational evolution of a shell and tube heat exchanger as a PCM thermal storage system." International Communications in Heat and Mass Transfer. 50, pp. 128-136. 2014.

https://doi.org/10.1016/j.icheatmasstransfer.2013.11.008

[7] Wang, Y., Wang, L., Xie, N., Lin, X., Chen, H. "Experimental study on the melting and solidification behavior of erythritol in a vertical shelland-tube latent heat thermal storage unit." International Journal of Heat and Mass Transfer. 99, pp. 770-781. 2016.

https://doi.org/10.1016/j.ijheatmasstransfer.2016.03.125

[8] Mosaffa, A. H., Talati, F., Basirat Tabrizi, H., Rosen, M. A. "Analytical modeling of PCM solidification in a shell and tube finned thermal storage for air conditioning systems." Energy and Buildings. 49, pp. 356-361. 2012. https://doi.org/10.1016/j.enbuild.2012.02.053

[9] Zhang, Y., Faghri, A. "Heat transfer enhancement in latent heat thermal energy storage system by using the internally finned tube." International Journal of Heat and Mass Transfer. 39 (15), pp. 3165-3173. 1996. https://doi.org/10.1016/0017-9310(95)00402-5

[10] Al-Abidi, A. A., Mat, S., Sopian, K., Sulaiman, M. Y., Mohammad, A. T. "Internal and external fin heat transfer enhancement technique for latent heat thermal energy storage in triplex tube heat exchangers." Applied Thermal Engineering. 53 (1), pp. 147-156. 2013.

https://doi.org/10.1016/j.applthermaleng.2013.01.011
[11] Tao, Y. B., He, Y. L., Qu, Z. G. "Numerical study on performance of molten salt phase change thermal energy storage system with enhanced tubes." Solar Energy. 86 (5), pp. 1155-1163. 2012.

https://doi.org/10.1016/j.solener.2012.01.004

[12] Regin, A. F., Solanki, S. C., Saini, J. S. "Latent heat thermal energy storage using cylindrical capsule: Numerical and experimental investigations." Renewable Energy. 31(13), pp. 2025-2041. 2006. https://doi.org/10.1016/j.renene.2005.10.011

[13] Campos-Celador, Á., Diarce, G., Zubiaga, J. T., Bandos, T. V., GarcíaRomero, A. M., López, L. M., Sala, J. M. "Design of a Finned Plate Latent Heat Thermal Energy Storage System for Domestic Applications." Energy Procedia. 48, pp. 300-308. 2014. https://doi.org/10.1016/j.egypro.2014.02.035

[14] Da Veiga, W. R. "Characteristics of a semicircular heat exchanger used in a water heated condenser pump." PhD Thesis, Rand Afrikaans University, South Africa. 2002. 